\title{
Is There a Chronic Elevation in Organ-Tissue Sleeping Metabolic Rate in Very Fit Runners?
}

\author{
Taishi Midorikawa ${ }^{1, *}$, Shigeho Tanaka ${ }^{2}$, Takafumi Ando ${ }^{2}$, Chiaki Tanaka ${ }^{1}$, Konishi Masayuki ${ }^{3}$, \\ Megumi Ohta ${ }^{4}$, Suguru Torii ${ }^{3}$ and Shizuo Sakamoto ${ }^{3}$ \\ 1 College of Health and Welfare, J.F. Oberlin University, 3758 Tokiwamachi, Machida, Tokyo 194-0294, Japan; \\ c-tanaka@obirin.ac.jp \\ 2 Department of Nutritional Science, National Institute of Health and Nutrition, \\ National Institutes of Biomedical Innovation, Health and Nutrition, 1-23-1 Toyama, Shinjuku-ku, \\ Tokyo 162-8636, Japan; tanakas@nih.go.jp (S.T.); takafumi_andy@yahoo.co.jp (T.A.) \\ 3 Faculty of Sport Sciences, Waseda University, 2-579-15 Mikajima, Tokorozawa, Saitama 359-1192, Japan; \\ m.konishi@aoni.waseda.jp (K.M.); shunto@waseda.jp (S.T.); s.sakamoto@waseda.jp (S.S.) \\ 4 School of International Liberal Studies, Chukyo University, 101 Tokodachi, Kaizu-cho, Toyota, \\ Aichi 470-0393, Japan; m-ohta@lets.chukyo-u.ac.jp \\ * Correspondence: taishi@obirin.ac.jp; Tel.: +81-42-797-8426
}

Received: 28 November 2015; Accepted: 22 March 2016; Published: 2 April 2016

\begin{abstract}
It is unclear whether the resting metabolic rate of individual organ-tissue in adults with high aerobic fitness is higher than that in untrained adults; in fact, this topic has been debated for years using a two-component model. To address this issue, in the present study, we examined the relationship between the measured sleeping energy expenditure (EE) by using an indirect human calorimeter (IHC) and the calculated resting EE (REE) from organ-tissue mass using magnetic resonance imaging, along with the assumed metabolic rate constants in healthy adults. Seventeen healthy male long-distance runners were recruited and grouped according to the median $\dot{\mathrm{V}} \mathrm{O}_{2}$ peak: very fit group $(>60 \mathrm{~mL} / \mathrm{min} / \mathrm{kg} ; n=8)$ and fit group $(<60 \mathrm{~mL} / \mathrm{min} / \mathrm{kg} ; n=9)$. Participants performed a graded exercise test for determining $\dot{\mathrm{V}}_{2}$ peak; X-ray absorptiometry and magnetic resonance imaging were used to determine organ-tissue mass, and IHC was used to determine sleeping EE. The calculated REE was estimated as the sum of individual organ-tissue masses multiplied by their metabolic rate constants. No significant difference was observed in the measured sleeping EE, calculated REE, and their difference, as well as in the slopes and intercepts of the two regression lines between the groups. Moreover, no significant correlation between $\mathrm{V}_{2}$ peak and the difference in measured sleeping EE and calculated REE was observed for all subjects. Thus, aerobic endurance training does not result in a chronic elevation in the organ-tissue metabolic rate in cases with $\dot{\mathrm{V}}_{2}$ peak of approximately $60 \mathrm{~mL} / \mathrm{min} / \mathrm{kg}$.
\end{abstract}

Keywords: sleeping energy expenditure; organ-tissue mass; $\dot{\mathrm{VO}}_{2}$ peak

\section{Introduction}

Sleeping energy expenditure (EE) is the minimum EE required to sustain body function. The sleeping EE of the entire body is an important component of total daily energy expenditure and is generally slightly lower than the resting EE (REE) in the lying or sitting position [1]. In cases with low activity-related energy expenditure, sleeping EE accounts for approximately $60 \%-70 \%$ of the total energy expenditure [2,3]. Hence, the variability in sleeping EE is closely associated with energy equilibrium. Moreover, the inter-individual variability in sleeping EE is reported to be small, probably due to the accuracy of using an indirect human calorimeter (IHC) for measurement in a stable condition [1]. 
Previous studies, which predicted REE by multiplying the mass measured using the magnetic resonance imaging (MRI) method and the assumed constant metabolic rate of each organ-tissue among healthy adults, indicated that the calculated REE from organ-tissue mass was well correlated with the measured REE using indirect calorimetry in young and middle-aged men and women, as well as in underweight and obese healthy adults [4-6]. The results suggested that the variability in organ-tissue mass is responsible for the variation in REE, and that the metabolic coefficients per unit organ-tissue mass remain almost constant for untrained adults. Thus, the REE of the entire body can be expressed as summation of the resting energy metabolism from individual organs and tissues in healthy young and middle-aged men and women.

A high sleeping EE and/or REE due to exercise training is likely to contribute to effective weight management, although the supporting evidence is controversial. Based on the REE model at the organ-tissue level, increased skeletal muscle (SM) mass and internal organ mass due to exercise training would be closely related to a high sleeping EE and/or REE. In fact, studies have shown that the high REE ( $>2000 \mathrm{kcal} /$ day) in Sumo wrestlers, with a fat-free mass (FFM) of approximately $80 \mathrm{~kg}$ and $\mathrm{VO}_{2}$ max of $30 \mathrm{~mL} / \mathrm{min} / \mathrm{kg}$, can be attributed to the presence of a larger absolute amount of low and high metabolically active tissue, such as the SM, liver, and kidney [7,8]. Hence, it is highly likely that changes in organ-tissue mass after exercise training can lead to an increase in REE (e.g., $13 \mathrm{kcal} / \mathrm{kg} /$ day for SM [9]).

Moreover, the increase in the absolute value of sleeping EE and/or REE via exercise training may also be caused by the enhancement of the resting metabolic rate of individual organ-tissue. A previous study indicated that exercise training results in a significant elevation in REE, without an increase in the FFM; however, it was noted that the time from the termination of the last exercise bout to REE measurement was a significant factor for REE elevation, and that long-term excess post-exercise $\mathrm{O}_{2}$ consumption may persist for up to $48 \mathrm{~h}$ [10]. In previous cross-sectional studies that did not have problems related to the variability of REE (e.g., age, gender, body composition, and time to measure REE), it was found that the resting metabolic rate per unit of FFM-a simple index of metabolic rate-was not related to the $\dot{\mathrm{VO}}_{2}$ max in young healthy women [11]. Moreover, over the last decade, it was found that aerobic endurance training does not affect REE and the REE adjusted for FFM [12,13], and that endurance exercise training prevents a seasonal decline in the absolute value of REE and the REE/FFM ratio [14]. It is unclear whether the resting metabolic rate of individual organ-tissue in adults with high aerobic fitness is higher than that in untrained adults; in fact, debates on this topic using the two-component model remain unresolved.

Furthermore, many previous studies indicated that variations in REE without increasing organ-tissue mass appear to be correlated with many physiological factors, such as thyroid status, circulating triiodothyronine $\left(\mathrm{T}_{3}\right)$, and thyroxine $\left(\mathrm{T}_{4}\right)$, which increase the metabolism of the various cells, as well as epinephrine and norepinephrine, which increase heat production $[10,14,15]$. Based on these findings, it is possible that the resting metabolic rate per unit organ-tissue mass is elevated by hormones, the release of which is stimulated by aerobic exercise.

In the present study, we aimed to assess whether there is a chronic elevation in organ-tissue sleeping metabolic rate due to the aerobic fitness level. Therefore, we examined the relationship between the measured sleeping EE by using IHC and the calculated REE from organ-tissue mass using MRI, as well as the assumed metabolic rate constants in healthy adults based on a previously published approach [4], including blood analysis.

\section{Materials and Methods}

\subsection{Subjects}

A total of 17 healthy male Japanese long distance runners aged 18-23 years were recruited for the study. The long distance runners had participated in regular training for an average of five years. None of the subjects had a history of smoking or cardiovascular, endocrine, or orthopaedic disorders; had 
ever tested positive for anabolic steroids; or had been taking any medication during the measurement period. All the subjects received a verbal and written description of the study and provided informed consent to participate prior to testing. The study protocol was approved by the Ethical Committee of Waseda University and the National Institute of Health and Nutrition, and was conducted according to the guidelines laid down in the Declaration of Helsinki.

\section{2. $\dot{\mathrm{VO}} 2$ peak Measurement}

Participants performed a graded exercise test to exhaustion on a treadmill (MAT-2700, Fukuda Denshi, Japan) to determine the $\mathrm{VO}_{2}$ peak. The graded exercise test was started at $1 \mathrm{~km} / \mathrm{h}$ and $0 \%$ slope, and the speed and slope of the treadmill were increased every minute by approximately 1 metabolic equivalent until the participants were exhausted [16,17]. During the exercise, a 12-lead electrocardiogram was electronically recorded (Stress Test System ML-6500, Fukuda Denshi, Japan), and the heart rates were derived from the RR interval. Pulmonary gas exchange parameters (oxygen uptake $\left(\dot{\mathrm{V}} \mathrm{O}_{2}\right)$, carbon dioxide output $\left(\dot{\mathrm{V}} \mathrm{CO}_{2}\right)$, and respiratory exchange ratio (RER)) were determined in a breath-by-breath assessment using a gas analyser (AE-300S, Minato Medical Science, Osaka, Japan). Maximal metabolic measurements and heart rate were recorded only if the participants met at least two of the following three criteria [18]: (1) achieved $\dot{\mathrm{VO}}_{2}$ plateau $(<150 \mathrm{~mL} / \mathrm{min})$ despite increasing the exercise intensity; (2) the highest heart rate measured during the last minute of the exercise was $>90 \%$ of the predicted maximal heart rate (220 - age (in years)); and (3) the highest RER during the final stage of the incremental exercise was $>1.10$.

\subsection{Anthropometry and Dual Energy X-ray Absorptiometry (DXA) Measurements}

Body mass was measured on a digital balance to the nearest $0.1 \mathrm{~kg}$, with the subjects wearing only minimal clothing, whereas the height was measured on a stadiometer to the nearest $0.1 \mathrm{~cm}$. Body mass index $\left(\mathrm{kg} / \mathrm{m}^{2}\right)$ was calculated as body weight $(\mathrm{kg})$ divided by the square of the height $(\mathrm{m})$. Total fat mass was measured using DXA (Delphi A-QDR, Hologic Inc., Bedford, MA, USA; Version 12.4:3 Auto Whole Body Fan Beam). The estimated coefficient of validation for DXA measurements from test-retest analysis was determined to be $<1 \%$.

\subsection{Measurement of Organ-Tissue Mass Using MRI}

The volumes of whole-body SM, the internal organs (liver and kidney), and the brain were measured using a General Electric Signa EXCITE VI 1.5 Tesla scanner (Milwaukee, WI, USA). A T1-weighted spin-echo, axial-plane sequence was employed, with a 500-ms repetition time and a 13.1-ms echo time, during breath holding scans and normal breathing scans. Subjects rested quietly in the magnet bore in the supine position with their hands placed on their abdomen. Contiguous transverse images with $1.0-\mathrm{cm}$ slice thicknesses $(0-\mathrm{cm}$ interslice gap) were obtained from the top of the head to the malleolus lateralis for each subject. Approximately five sets of acquisitions were performed, extending from the top of the head to the femoral head, during breath holding (approximately $30 \mathrm{~s} / \mathrm{set}$ ). The other sets of acquisitions were obtained from the femoral head to the malleolus lateralis during normal breathing [19]. All images (approximately 170 slices per person) were traced by a highly trained technician, while including the SM, brain, and abdominal organ segments and excluding connective tissue, blood vessels, and fat tissue. MR images were analysed using ZedView software (LEXI Co., Ltd, Tokyo, Japan) for segmentation and calculation of the cross-sectional tissue areas.

The volumes of the SM, liver, kidney, and brain were calculated from the sum of the cross-sectional area $\left(\mathrm{cm}^{2}\right)$ determined by tracing the images, and then multiplying the value by the slice thickness $(1 \mathrm{~cm})$. The volumes $\left(\mathrm{cm}^{3}\right)$ were converted to masses $(\mathrm{kg})$ by using the following densities: $1.041 \mathrm{~g} / \mathrm{cm}^{3}$ for the SM [20], $1.060 \mathrm{~g} / \mathrm{cm}^{3}$ for liver, $1.050 \mathrm{~g} / \mathrm{cm}^{3}$ for kidney, and $1.036 \mathrm{~g} / \mathrm{cm}^{3}$ for brain [21]. The estimated coefficient of validation (CV) for SM volume measurements from a test-retest analysis was determined to be $2 \%$ [19]. The percentage of difference in measurements for the same scan on two 
separate days by the same technician was $0.3 \%$ for the liver, $0.5 \%$ for the kidney, and $0.6 \%$ for the brain $(n=5)$.

Since the constantly pulsing heart produced artifacts, heart mass $(\mathrm{g})$ was estimated from the height and body mass by using the following formula: $22.81 \times$ height $(\mathrm{m}) \times$ body mass $^{0.5}(\mathrm{~kg})-4.15$ [22]. Adipose tissue mass was calculated from fat mass with the assumption that $85 \%$ of the adipose tissue was fat and $15 \%$ of the adipose tissue consisted of the remaining calculated fat-free component [23]. Residual mass was calculated as the total body mass minus the sum of the SM, adipose tissue, brain, liver, kidney, and heart masses, as the total body mass was considered to include the sum of the organ masses. Accordingly, residual mass was considered to be composed of bone, blood, skin, intestine, connective tissue, and lung tissue [20].

\subsection{Measurement of Sleeping EE Using IHC}

The subjects entered the IHC chamber at 18:00-19:00 on the study day, had dinner at 18:30 or 19:00, went to bed at 23:00 after sedentary activities, and slept until 07:00 the following morning [1]. Each subject was provided a standardized dinner to meet their EE during their stay in the chamber based on the predicted basal metabolic rate and an assumed physical activity level of 1.5 [1]. None of the subjects performed any exercise for $>48 \mathrm{~h}$ prior to testing. Details of the IHC method have been previously published [24,25]. In brief, the respiratory chamber comprised an air-tight room $(20,000$ or 15,000 L) that was equipped with a bed, desk, chair, television with video deck, compact disc player, telephone, toilet, and sink. The temperature and relative humidity in the room were controlled at $25{ }^{\circ} \mathrm{C}$ and $55 \%$, respectively. The $\mathrm{O}_{2}$ and $\mathrm{CO}_{2}$ concentrations (maintained by air supply and exhaust) were measured using mass spectrometry. For each experiment, the gas analyser (ARCO-1000A-CH; Arco System, Inc., Kashiwa, Japan) was initially calibrated using a certified gas mixture and atmospheric air. The flow rate of exhaust from the chamber was assessed using a pneumotachograph (FLB1; Arco System, Inc., Kashiwa, Japan). The flow meter was calibrated before each measurement, and the flow rate was maintained at $\sim 60 \mathrm{~L} / \mathrm{min}$. $\dot{\mathrm{V}} \mathrm{O}_{2}$ and $\dot{\mathrm{V}} \mathrm{CO}_{2}$ were determined based on the flow rate of exhaust from the chamber as well as the concentrations of the inlet and outlet air from the chamber, respectively [26]. The values of $\dot{\mathrm{V}} \mathrm{O}_{2}$ and $\dot{\mathrm{V}} \mathrm{CO}_{2}$ were recorded under conditions of standard temperature and pressure and under dry conditions. EE was estimated from $\dot{\mathrm{V}}_{2}$ and $\dot{\mathrm{V}} \mathrm{CO}_{2}$ using Weir's equation [27]. The accuracy and precision of the IHC for measuring EE, as determined by the alcohol combustion test, was $99.8 \% \pm 0.5 \%$ (mean \pm standard deviation (SD)) in $6 \mathrm{~h}$ and $99.4 \% \pm 3.1 \%$ in $30 \mathrm{~min}$. Sleeping EE was defined as the minimum EE recorded over $3 \mathrm{~h}$ of sleep between 23:00 and 07:00.

\subsection{Calculation of REE}

REE was calculated as the sum of seven body compartments (SM, adipose tissue, brain, liver, kidney, heart, and residual mass) multiplied by the corresponding tissue-respiration rate, which is based on specific reported tissue-metabolic rates [9]. The calculated REE was computed using the following equation [4]: calculated REE (kcal/day $)=(13 \times \mathrm{SM}$ mass $)+(4.5 \times$ adipose tissue mass $)+(240 \times$ brain mass $)+(200 \times$ liver mass $)+(440 \times$ kidney mass $)+(440 \times$ heart mass $)+$ $(12 \times$ residual mass).

\subsection{Blood Collection and Analysis}

Blood samples were collected into tubes containing thrombin for analysing the levels of thyroid-stimulating hormone (TSH), total and free $\mathrm{T}_{3}$, and total and free $\mathrm{T}_{4}$, as well as into tubes containing EDTA-2Na for analysing the levels of plasma epinephrine and norepinephrine. The blood samples in both tubes were centrifuged (3000 rpm for $10 \mathrm{~min}$ ) after collection, and the serum and plasma were transferred into plastic tubes. Serum and plasma samples were immediately stored at a temperature of $<-30{ }^{\circ} \mathrm{C}$ until further analysis. The concentrations of serum TSH and total and free $\mathrm{T}_{3}$ and $\mathrm{T}_{4}$ were measured using an electrochemiluminescence immunoassay. Plasma epinephrine and 
norepinephrine concentrations were measured using high-performance liquid chromatography. Blood samples were analysed by SRL, Inc. (Tokyo, Japan).

\subsection{Statistical Analysis}

Results are expressed as means \pm standard deviation for all variables. A total of 17 subjects were assigned to two groups according to the median $\dot{\mathrm{VO}}_{2}$ peak of $60 \mathrm{~mL} / \mathrm{min} / \mathrm{kg}$ : very fit group $(>60 \mathrm{~mL} / \mathrm{min} / \mathrm{kg} ; n=8)$ and fit group $(<60 \mathrm{~mL} / \mathrm{min} / \mathrm{kg} ; n=9)$. The differences between the two groups were tested for significance by using an unpaired $t$-test, and were illustrated by using a box-plot diagram. Pearson's product-moment analysis was used to compare the measured sleeping EE and calculated REE in the very fit and fit runners, respectively. The difference in the slopes and intercepts of the regression lines were tested between very fit runners and fit runners by using analysis of covariance. Bland-Altman analysis was conducted by plotting the differences in the measured sleeping EE and calculated REE values against the corresponding mean values [28]. In all the subjects, Pearson's product-moment analysis was used to assess the relationship of $\dot{\mathrm{VO}}_{2}$ peak with the difference in measured sleeping EE and calculated REE. Statistical analyses were performed using SPSS for Windows (IBM SPSS version 22.0; SPSS Inc., Chicago, IL, USA). Differences were regarded as significant when the probabilities were $<0.05$.

\section{Results}

There was no difference in mean age, standing height, body mass, BMI, fat mass, and FFM between very fit and fit runners, although body fat percentage was different between these groups; moreover, very fit runners had a higher $\mathrm{VO}_{2}$ peak as compared to the fit runners (Table 1). Organ-tissue mass (SM, adipose tissue, brain, liver, kidney, heart, and residual mass) and the ratio of SM mass $(45.9 \%$ vs. $45.9 \%)$, brain ( $2.9 \%$ vs. $3.1 \%)$, liver ( $2.8 \%$ vs. $2.6 \%)$, and kidney $(0.6 \%$ vs. $0.6 \%)$ to FFM were also similar between very fit and fit runners (Table 2). Moreover, the measured sleeping EE to FFM ratio $(26.7 \pm 2.0 \mathrm{kcal} / \mathrm{kg} /$ day $)$ in very fit runners was not significantly different from that in fit runners $(28.4 \pm 2.3 \mathrm{kcal} / \mathrm{kg} /$ day; $p=0.07)$.

Table 1. Subject characteristics.

\begin{tabular}{|c|c|c|c|}
\hline & Very Fit Runners & Fit Runners & $p$ \\
\hline & $n=8$ & $n=9$ & \\
\hline Age (years) & $21 \pm 1$ & $20 \pm 1$ & n.s. \\
\hline Standing height $(\mathrm{cm})$ & $170.8 \pm 4.7$ & $170.9 \pm 5.3$ & n.s. \\
\hline Body mass $(\mathrm{kg})$ & $58.0 \pm 6.7$ & $55.0 \pm 4.1$ & n.s. \\
\hline $\mathrm{BMI}\left(\mathrm{kg} / \mathrm{m}^{2}\right)$ & $19.8 \pm 1.7$ & $18.8 \pm 1.1$ & n.s. \\
\hline Fat $(\%)$ & $8.5 \pm 0.9$ & $10.9 \pm 2.7$ & $<0.05$ \\
\hline Fat mass $(\mathrm{kg})$ & $4.9 \pm 0.9$ & $6.0 \pm 1.5$ & n.s. \\
\hline Fat-free mass (FFM) (kg) & $53.0 \pm 5.9$ & $49.0 \pm 4.2$ & n.s. \\
\hline Peak heart rate (beats / min) & $180 \pm 10$ & $181 \pm 8$ & n.s. \\
\hline Peak RER & $1.17 \pm 0.04$ & $1.25 \pm 0.08$ & $<0.05$ \\
\hline$\dot{\mathrm{V}} \mathrm{O}_{2}$ peak (mL/min) & $3860 \pm 320$ & $3205 \pm 292$ & $<0.01$ \\
\hline$\dot{\mathrm{V}} \mathrm{O}_{2}$ peak $(\mathrm{mL} / \mathrm{kg} / \mathrm{min})$ & $65.2 \pm 3.4$ & $56.7 \pm 2.1$ & $<0.01$ \\
\hline
\end{tabular}

BMI: body mass index; RER: respiratory exchange ratio.

The measured sleeping EE, calculated REE, and their difference in very fit runners was not significantly different from those in fit runners (Table 3, Figure 1). A significant relationship between measured sleeping EE and calculated REE was observed in the 2 groups (very fit runners: $r=0.79$, $p<0.05$; fit runners: $r=0.72, p<0.05$ ) (Figure 2). The slopes and intercepts of the two regression lines did not differ between the groups. A Bland-Altman plot showed no significant trend in both very fit and fit runners (Figure 3). Moreover, a significant correlation between $\dot{\mathrm{VO}}_{2}$ peak and the difference in measured sleeping EE and calculated REE was not observed in all subjects (Figure 4). In addition, 
except for free $\mathrm{T}_{4}$ levels, none of the blood analysis parameters were significantly different in the very fit and fit runners (Table 4).

Table 2. Body composition at the organ-tissue level.

\begin{tabular}{cccc}
\hline \multirow{2}{*}{ Organ-Tissue Mass (kg) } & Very Fit Runners & Fit Runners & \multirow{2}{*}{$\boldsymbol{p}$} \\
\cline { 2 - 3 } & $\boldsymbol{n}=\mathbf{8}$ & $\boldsymbol{n}=\mathbf{9}$ & \\
\hline Skeletal muscle & $24.4 \pm 3.2$ & $22.5 \pm 2.3$ & n.s. \\
Adipose tissue & $5.9 \pm 1.1$ & $7.2 \pm 1.8$ & n.s. \\
Liver & $1.48 \pm 0.32$ & $1.26 \pm 0.12$ & n.s. \\
Brain & $1.54 \pm 0.13$ & $1.52 \pm 0.10$ & n.s. \\
Heart $^{2}$ & $0.29 \pm 0.02$ & $0.28 \pm 0.02$ & n.s. \\
Kidney $^{\text {Residual }}{ }^{3}$ & $0.30 \pm 0.08$ & $0.30 \pm 0.04$ & n.s. \\
\hline
\end{tabular}

${ }^{1}$ We have assumed that $85 \%$ of adipose tissue is fat and $15 \%$ of adipose tissue is the remaining calculated fat-free component, as reported by Heymsfield et al. [23]; ${ }^{2}$ Heart mass is calculated as $(22.81 \times$ Height [m] $\times$ Body mass $\left.{ }^{0.5}[\mathrm{~kg}]-4.15\right) / 1000$, as reported by Ogiu et al. [22]; ${ }^{3}$ Residual mass was calculated as body mass minus the sum of the other measured mass components.

Table 3. Measured sleeping energy expenditure and calculated resting energy expenditure.

\begin{tabular}{|c|c|c|c|}
\hline & Very Fit Runners & Fit Runners & \multirow[t]{2}{*}{$p$} \\
\hline & $n=8$ & $n=9$ & \\
\hline Measured sleeping EE (kcal/day) & $1412 \pm 179$ & $1392 \pm 139$ & n.s. \\
\hline Calculated REE (kcal/day) & $1559 \pm 176$ & $1464 \pm 95$ & n.s. \\
\hline Difference (Measured - Calculated) & $-147 \pm 115$ & $-72 \pm 97$ & n.s. \\
\hline
\end{tabular}

EE: energy expenditure; REE: resting energy expenditure.

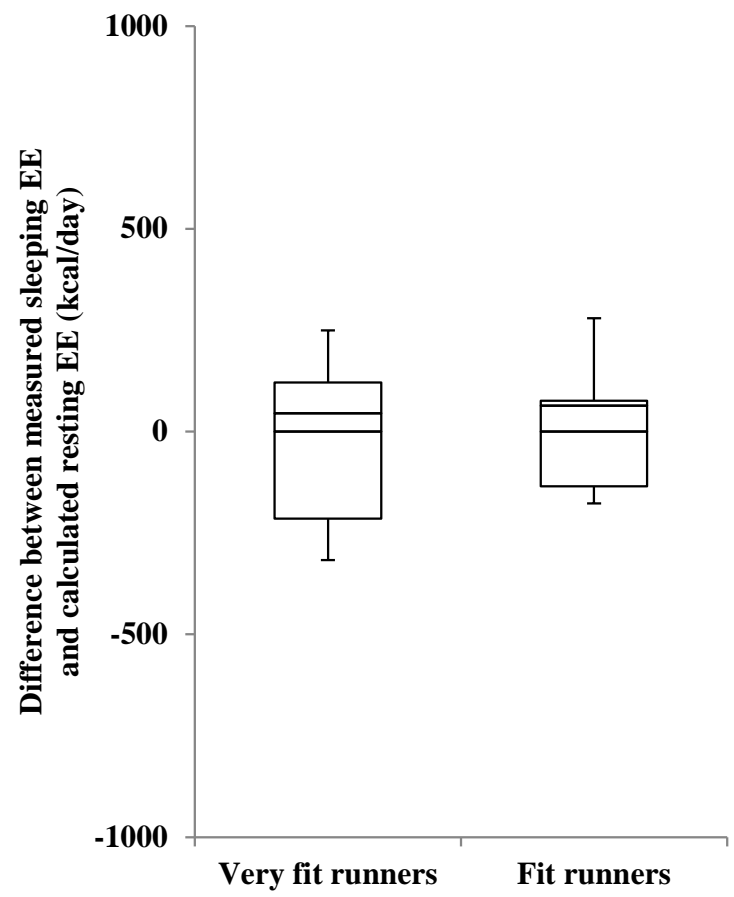

Figure 1. Box-plot diagram for comparing measured sleeping energy expenditure and estimated resting energy expenditure. EE: energy expenditure; REE: resting energy expenditure. 


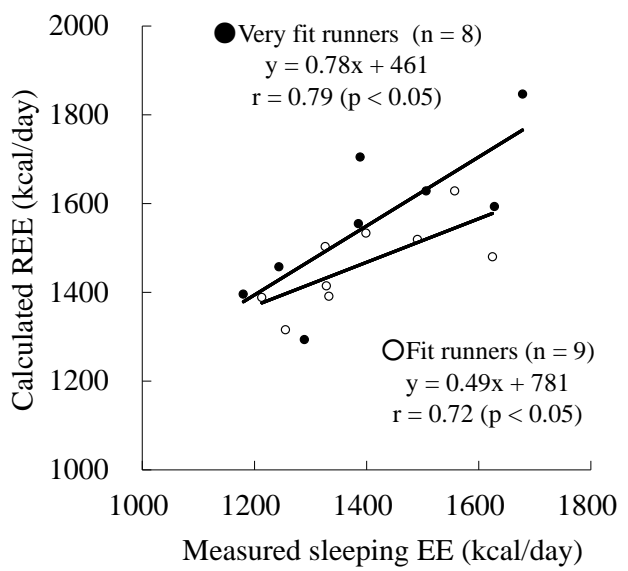

Figure 2. Relationship between the measured sleeping energy expenditure and calculated resting energy expenditure. EE: energy expenditure; REE: resting energy expenditure.

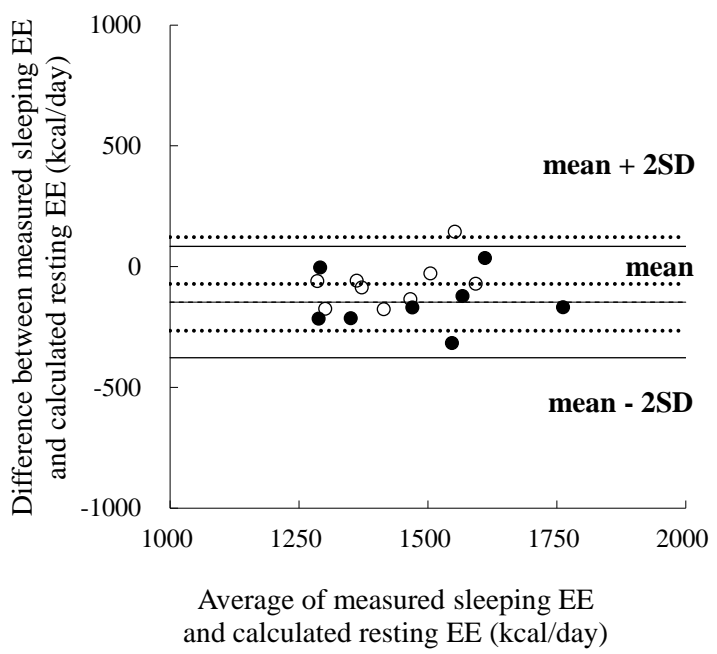

Figure 3. Bland-Altman analysis for comparing measured sleeping energy expenditure and estimated resting energy expenditure. EE: energy expenditure; REE: resting energy expenditure; •: very fit runners; $\bigcirc$ : fit runners.

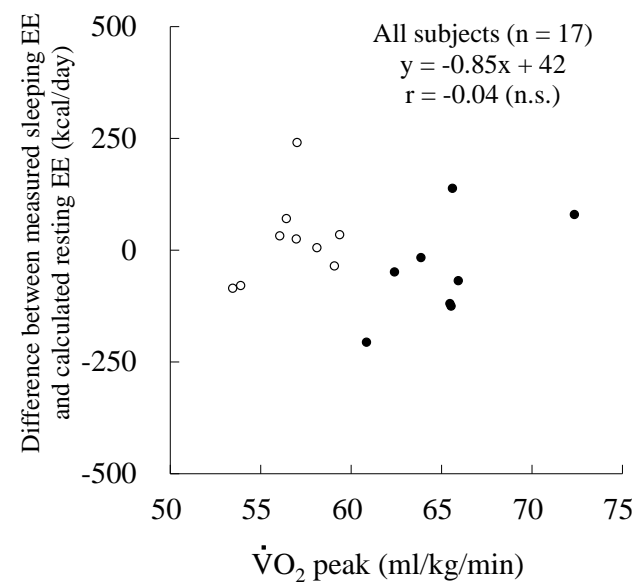

Figure 4. Relationship between $\mathrm{VO}_{2}$ peak and the difference in measured sleeping energy expenditure and calculated resting energy expenditure. EE: energy expenditure; $\bullet$ : very fit runners; $\bigcirc$ : fit runners. 
Table 4. Blood analyses.

\begin{tabular}{cccc}
\hline & Very Fit Runners & Fit Runners & \multirow{2}{*}{$\boldsymbol{p}$} \\
\cline { 2 - 3 } & $\boldsymbol{n}=\mathbf{8}$ & $\boldsymbol{n}=\mathbf{9}$ & \\
\hline TSH $(\mu \mathrm{IU} / \mathrm{mL})$ & $1.89 \pm 0.94$ & $2.02 \pm 1.21$ & n.s. \\
${\text { Total } \mathrm{T}_{3}(\mathrm{ng} / \mathrm{mL})}$ & $0.96 \pm 0.94$ & $1.05 \pm 0.16$ & n.s. \\
${\text { Free } \mathrm{T}_{3}(\mathrm{pg} / \mathrm{mL})}$ & $2.93 \pm 0.70$ & $3.15 \pm 0.33$ & n.s. \\
${\text { Total } \mathrm{T}_{4}(\mu \mathrm{g} / \mathrm{dL})}_{\text {Free } \mathrm{T}_{4}(\mathrm{ng} / \mathrm{dL})}^{6.54 \pm 1.10}$ & $7.36 \pm 0.68$ & n.s. \\
Epinephrine $(\mathrm{pg} / \mathrm{mL})$ & $1.13 \pm 0.19$ & $1.33 \pm 0.79$ & $<0.05$ \\
Norepinephrine $(\mathrm{pg} / \mathrm{mL})$ & $35 \pm 13$ & $59 \pm 57$ & n.s. \\
\hline
\end{tabular}

TSH: thyroid-stimulating hormone; T3: triiodothyronine; T4: thyroxine.

\section{Discussion}

In the present study, we assessed whether there is a chronic elevation in the organ-tissue sleeping metabolic rate according to the aerobic fitness level by comparing measured sleeping EE and calculated REE between very fit and fit runners and by analysing the relationship of $\mathrm{VO}_{2}$ peak with the difference in measured sleeping EE and calculated resting EE for all subjects. We did not observe any significant difference in the measured sleeping EE, calculated REE, and their difference, as well as in the slopes and intercepts of the two regression lines between the very fit and fit runners. Moreover, Bland-Altman analysis did not show any significant trend for very fit and fit runners. Furthermore, a significant correlation between $\dot{\mathrm{V}}_{2}$ peak and the difference in measured sleeping EE and calculated REE was not observed in all the subjects. These results suggest that there is no chronic elevation in the organ-tissue resting metabolic rate according to the aerobic fitness level. Moreover, the results of the present study indicated that physiological factors, such as serum $\mathrm{TSH}$, total and free $\mathrm{T}_{3}$ and $\mathrm{T}_{4}$, and plasma epinephrine and norepinephrine concentrations, are not involved in the chronic elevation of the organ-tissue metabolic rate in aerobically trained populations.

A previous study with a cross-sectional design did not indicate any evidence regarding the presence of a positive relationship between REE and $\mathrm{V}_{2} \max (32-65 \mathrm{~mL} / \mathrm{min} / \mathrm{kg})$ in young adult women, after statistically controlling for the influence of FFM [11]. In contrast, 12-week endurance exercise training (jogging and / or running for 3-4 days/week, 25-40 min/session, at $60 \%-80 \% \dot{\mathrm{V}}_{2}$ max) in male participants aged 19-32 years appeared to prevent a seasonal decline in the absolute value of REE and the REE/FFM ratio; in that study, no significant change was observed in the exercise group, although significant decreases in the REE and the REE/FFM ratio were observed in the control group [14]. Furthermore, a six-month endurance training program (walking, jogging, cycling, and rowing for 3-4 days/week, $45-60 \mathrm{~min} /$ session, at 70\%-85\% maximal heart rate) in postmenopausal African-American and Caucasian women [12] and 12-month aerobic endurance training (walking or jogging for 3 days/week, $45 \mathrm{~min} /$ session, at 77\% maximal heart rate) in previously untrained men and women [13] did not appear to affect REE and the REE adjusted for FFM. Based on the results of the present and previous studies, it appears that aerobic fitness training does not lead to an obvious chronic elevation of the organ-tissue metabolic rate.

The FFM is known as a major determinant of sleeping EE and/or REE. REE is often adjusted per unit FFM (REE/FFM) in order to compare individuals with different body sizes, and the REE/FFM ratio is used as a substitute for the organ-tissue resting metabolic rate. Moreover, the FFM is known to account for between $50 \%$ and $70 \%$ of the individual variation [10], and because ratio normalization is highly prone to confounding owing to a non-zero y-intercept for the relationship between REE and FFM, studies using appropriate regression methods such as analysis of covariance are needed to better clarify the relationship between REE and FFM. Nevertheless, REE/FFM can be used as a simple index for comparing between subjects with similar FFM. Under these conditions, it was reported that the REE/FFM in normal untrained populations is apparently smaller for individuals with a greater 
FFM [23]. To explain this association between FFM and REE, it was proposed that a reduction in the proportion of internal organ-tissue mass to FFM is coupled with an increase in the proportion of skeletal muscle (SM) mass in untrained individuals [4,23]. Hence, the proportion of low metabolically active tissue (e.g., SM) and high metabolically active tissue (e.g., liver and kidney), relative to the FFM, could account for the REE/FFM ratio in normal untrained populations [23]. In the present study, we observed that the sleeping EE to FFM ratio in very fit runners was not significantly different from that in fit runners. Moreover, there were no differences in the absolute values of the SM, liver, and kidney masses (which affect the REE/FFM ratio), as well as their ratios to FFM, between very fit runners and fit runners in the present study. Thus, our findings indicate that endurance exercise training does not induce a huge increase in low and high metabolically active tissue (e.g., SM, liver, and kidney) or an elevation in the REE/FFM ratio.

There are three possible limitations of this study. First, we assumed that the previously reported value of resting metabolic rate for each organ-tissue was identical among individuals. As the variation in the resting metabolic rate is correlated with many physiological and genetic factors [10], we cannot exclude the possibility that the organ-tissue energy expenditure constants have some marginal error. Hence, further research is needed to directly measure the resting metabolic rate for each organ-tissue. Second, although MRI with $1.0-\mathrm{cm}$ slice thicknesses (0-cm interslice gap) is a precise and reliable method for measuring the total body SM mass in adults [19], contiguous transverse images with $<0.5-\mathrm{cm}$ slice thicknesses are needed to accurately estimate the masses of the brain, liver and kidneys. Moreover, as the estimation of heart mass from the body mass may contain errors, the heart mass should be more precisely assessed using ECG-triggered MRI (with an assumed metabolic rate of $440 \mathrm{kcal} / \mathrm{kg} /$ day). Third, the definition of sleeping EE and the REE calculation may be confusing. As reported in a previous study, if the sleeping EE was calculated using the formula REE $\times 0.935$ [1] (which is the average value obtained using IHC in 71 Japanese male subjects with an average age of 36 years), we need to compare the measured- and calculated-sleeping EE in the same field. In that analysis, we noted that: (1) there was no difference between the measured- and calculated-sleeping EE in both very fit $(1412 \pm 179$ vs. $1458 \pm 165 \mathrm{kcal} /$ day, $p=0.29)$ and fit runners $(1392 \pm 139$ vs. $1369 \pm 89 \mathrm{kcal} /$ day, $p=0.49$ ); (2) a significant relationship was observed between the measured- and calculated-sleeping EE in the two groups (very fit runners: $r=0.79, p<0.05$; fit runners: $r=0.72$, $p<0.05)$; and (3) a Bland-Altman plot showed no significant trend in both very fit runners $(r=0.14$, $p=0.75)$ and fit runners $(r=0.55, p=0.12)$, as well as in all the subjects $(r=0.20, p=0.43)$. These results also suggest that the resting metabolic rate of individual organ-tissue in aerobically trained populations with a $\dot{\mathrm{VO}}_{2}$ max of approximately $60 \mathrm{~mL} / \mathrm{min} / \mathrm{kg}$ was similar to that in untrained subjects.

\section{Conclusions}

In conclusion, in the present study, we sought to determine whether the resting metabolic rate of individual organ-tissue in very fit adults is higher than that in fit subjects by using MRI, IHC, and blood analysis. Our findings suggest that aerobic endurance training does not have any role in the chronic elevation of the organ-tissue metabolic rate in cases with a $\dot{\mathrm{VO}}_{2} \mathrm{max}$ of approximately $60 \mathrm{~mL} / \mathrm{min} / \mathrm{kg}$.

Acknowledgments: We would like to sincerely thank the subjects who participated in this study. We would also like to thank Hiroki Tabata for his effort in recruiting the subjects. We wish to thank the members of the National Institute of Health and Nutrition, particularly Hiroko Kogure, for her help in data acquisition and analyses. This study was supported in part by JSPS KAKENHI Grant Number 20240064 and 24680069.

Author Contributions: The contribution of each author to the manuscript is as follows: T.M. designed and conducted the research, analysed the data, and wrote the paper. S.T., T.A., C.T., K.M., M.O., S.T., and S.S. conducted the research and analysed the data.

Conflicts of Interest: The authors declare no conflict of interest. 


\section{Abbreviations}

$\begin{array}{ll}\text { EE } & \text { energy expenditure } \\ \text { IHC } & \text { indirect human calorimeter } \\ \text { REE } & \text { resting energy expenditure } \\ \text { FFM } & \text { fat-free mas } \\ \text { SM } & \text { skeletal muscle } \\ \text { MRI } & \text { magnetic resonance imaging } \\ \dot{V O}_{2} & \text { oxygen uptake } \\ \dot{V}_{2} O_{2} & \text { carbon dioxide output } \\ \mathrm{RER}_{\mathrm{DXA}} & \text { respiratory exchange ratio } \\ \mathrm{CV} & \text { dual energy X-ray absorptiometry } \\ \mathrm{TSH} & \text { thyroid-stimulating hormone } \\ \mathrm{T}_{3} & \text { triiodothyronine } \\ \mathrm{T}_{4} & \text { thyroxine } \\ \text { ECG } & \text { electrocardiogram }\end{array}$

\section{References}

1. Ganpule, A.A.; Tanaka, S.; Ishikawa-Takata, K.; Tabata, I. Interindividual variability in sleeping metabolic rate in Japanese subjects. Eur. J. Clin. Nutr. 2007, 61, 1256-1261. [CrossRef] [PubMed]

2. Ravussin, E.; Bogardus, C. Relationship of genetics, age, and physical fitness to daily energy expenditure and fuel utilization. Am. J. Clin. Nutr. 1989, 49, 968-975. [PubMed]

3. Ishikawa-Takata, K.; Tabata, I.; Sasaki, S.; Rafamantanantsoa, H.H.; Okazaki, H.; Okubo, H.; Tanaka, S.; Yamamoto, S.; Shirota, T.; Uchida, K.; et al. Physical activity level in healthy free-living Japanese estimated by doubly labelled water method and International Physical Activity Questionnaire. Eur. J. Clin. Nutr. 2008, 62, 885-891. [CrossRef] [PubMed]

4. Gallagher, D.; Belmonte, D.; Deurenberg, P.; Wang, Z.; Krasnow, N.; Pi-Sunyer, F.X.; Heymsfield, S.B. Organ-tissue mass measurement allows modeling of REE and metabolically active tissue mass. Am. J. Physiol. 1998, 275, 249-258.

5. Illner, K.; Brinkmann, G.; Heller, M.; Bosy-Westphal, A.; Muller, M.J. Metabolically active components of fat free mass and resting energy expenditure in nonobese adults. Am. J. Physiol. Endocrinol. Metab. 2000, 278, 308-315.

6. Bosy-Westphal, A.; Reinecke, U.; Schlorke, T.; Illner, K.; Kutzner, D.; Heller, M.; Muller, M.J. Effect of organ and tissue masses on resting energy expenditure in underweight, normal weight and obese adults. Int. J. Obes. Relat. Metab. Disord. 2004, 28, 72-79. [CrossRef] [PubMed]

7. Beekley, M.D.; Abe, T.; Kondo, M.; Midorikawa, T.; Yamauchi, T. Comparison of maximum aerobic capacity and body composition of elite Sumo wrestlers to elite athletes in combat and other sports. J. Sports Sci. Med. 2006, 5, 13-20. [PubMed]

8. Midorikawa, T.; Kondo, M.; Beekley, M.D.; Koizumi, K.; Abe, T. High REE in Sumo wrestlers attributed to large organ-tissue mass. Med. Sci. Sports Exerc. 2007, 39, 688-693. [CrossRef] [PubMed]

9. Elia, M. The inter-organ flux of substrates in fed and fasted man, as indicated by arterio-venous balance studies. Nutr. Res. Rev. 1991, 4, 3-31. [CrossRef] [PubMed]

10. Speakman, J.R.; Selman, C. Physical activity and resting metabolic rate. Proc. Nutr. Soc. 2003, 62, 621-634. [CrossRef] [PubMed]

11. Smith, D.A.; Dollman, J.; Withers, R.T.; Brinkman, M.; Keeves, J.P.; Clark, D.G. Relationship between maximum aerobic power and resting metabolic rate in young adult women. J. Appl. Physiol. 1997, 82, 156-163. [PubMed] 
12. Santa-Clara, H.; Szymanski, L.; Ordille, T.; Fernhall, B. Effects of exercise training on resting metabolic rate in postmenopausal African American and Caucasian women. Metabolism 2006, 55, 1358-1364. [CrossRef] [PubMed]

13. Scharhag-Rosenberger, F.; Meyer, T.; Walitzek, S.; Kindermann, W. Effects of one year aerobic endurance training on resting metabolic rate and exercise fat oxidation in previously untrained men and women. Metabolic endurance training adaptations. Int. J. Sports Med. 2010, 31, 498-504. [CrossRef] [PubMed]

14. Lee, M.G.; Sedlock, D.A.; Flynn, M.G.; Kamimori, G.H. Resting metabolic rate after endurance exercise training. Med. Sci. Sports Exerc. 2009, 41, 1444-1451. [CrossRef] [PubMed]

15. William, D.M.; Frank, I.K.; Victor, L.K. Exercise Physiology: Nutrition, Energy, and Human Performance, 7th ed.; Lippincott Williams \& Wilkins: Philadelphia, PA, USA, 2010.

16. Konishi, M.; Takahashi, M.; Endo, N.; Numao, S.; Takagi, S.; Miyashita, M.; Midorikawa, T.; Suzuki, K.; Sakamoto, S. Effect of one night of sleep deprivation on maximal fat oxidation during graded exercise. J. Phys. Fitness Sports Med. 2013, 2, 121-126. [CrossRef]

17. Konishi, M.; Takahashi, M.; Endo, N.; Numao, S.; Takagi, S.; Miyashita, M.; Midorikawa, T.; Suzuki, K.; Sakamoto, S. Effects of sleep deprivation on autonomic and endocrine functions throughout the day and on exercise tolerance in the evening. J. Sports Sci. 2013, 31, 248-255. [CrossRef] [PubMed]

18. Tanaka, K.; Takeshima, N.; Kato, T.; Niihata, S.; Ueda, K. Critical determinants of endurance performance in middle-aged and elderly endurance runners with heterogeneous training habits. Eur. J. Appl. Physiol. Occup. Physiol. 1990, 59, 443-449. [CrossRef] [PubMed]

19. Abe, T.; Kearns, C.F.; Fukunaga, T. Sex differences in whole body skeletal muscle mass measured by magnetic resonance imaging and its distribution in young Japanese adults. Br. J. Sports Med. 2003, 37, 436-440. [CrossRef] [PubMed]

20. Snyder, W.S.; Cooke, M.J.; Nasset, E.S.; Karhausen, L.R.; Howells, G.P.; Tipton, I.H. Report of the Task Group on Reference Man; Pergamon: Oxford, UK, 1975; pp. 112, 282-285.

21. Duck, F.A. Physical Properties of Tissue; Academic press: New York, NY, USA, 1990; p. 138.

22. Ogiu, N.; Nakamura, Y.; Ijiri, I.; Hiraiwa, K.; Ogiu, T. A statistical analysis of the internal organ weights of normal Japanese people. Health Phys. 1997, 72, 368-383. [CrossRef] [PubMed]

23. Heymsfield, S.B.; Gallagher, D.; Kotler, D.P.; Wang, Z.; Allison, D.B.; Heshka, S. Body-size dependence of resting energy expenditure can be attributed to nonenergetic homogeneity of fat-free mass. Am. J. Physiol. Endocrinol. Metab. 2002, 282, 132-138.

24. Futami, J.; Tanaka, S.; Yamamura, C.; Oka, J.; Ishikawa-Takata, K.; Kashiwazaki, H. Measurement of energy expenditure by whole-body indirect human calorimeter -evaluation of validity and error factors. Nippon Eiyo Shokuryo Gakkaishi (J. Jpn. Soc. Nutr. Food Sci.) 2003, 56, 229-236. (In Japanese). [CrossRef]

25. Yamamura, C.; Tanaka, S.; Futami, J.; Oka, J.; Ishikawa-Takata, K.; Kashiwazaki, H. Activity diary method for predicting energy expenditure as evaluated by a whole-body indirect human calorimeter. J. Nutr. Sci. Vitaminol. 2003, 49, 262-269. [CrossRef] [PubMed]

26. Usui, C.; Ando, T.; Ohkawara, K.; Miyake, R.; Oshima, Y.; Hibi, M.; Oishi, S.; Tokuyama, K.; Tanaka, S. Validity and reproducibility of a novel method for time-course evaluation of diet-induced thermogenesis in a respiratory chamber. Physiol. Rep. 2015, 3, e12410. [CrossRef] [PubMed]

27. Weir, J.B. New methods for calculating metabolic rate with special reference to protein metabolism. J. Physiol. 1949, 109, 1-9. [CrossRef] [PubMed]

28. Bland, J.M.; Altman, D.G. Statistical methods for assessing agreement between two methods of clinical measurement. Lancet 1986, 1, 307-310. [CrossRef]

(C) 2016 by the authors; licensee MDPI, Basel, Switzerland. This article is an open access article distributed under the terms and conditions of the Creative Commons by Attribution (CC-BY) license (http:/ / creativecommons.org/licenses/by/4.0/). 